International Journal of Electrical Engineering and Technology (IJEET)

Volume 11, Issue 4, June 2020, pp. 384-391, Article ID: IJEET_11_04_043

Available online at https://iaeme.com/Home/issue/IJEET? Volume $=11 \&$ Issue $=4$

ISSN Print: 0976-6545 and ISSN Online: 0976-6553

DOI: https://doi.org/10.34218/IJEET.11.4.2020.043

(C) IAEME Publication

Scopus Indexed

\title{
PHC CONTROL METHOD FOR SHUNT ACTIVE POWER FILTERS IN THREE-PHASE FOUR- WIRE SYSTEMS
}

\author{
A. Muthuraman \\ Associate Professor, Department of Electrical and Electronics Engineering, \\ Mailam Engineering College, Mailam, Tindivanam, Tamil Nadu, India. \\ M. Saravana Kumar \\ Assistant Professor, Department of Electrical and Electronics Engineering, \\ Mailam Engineering College, Mailam, Tindivanam, TamilNadu, India.
}

\begin{abstract}
This paper describes the Control method of calculating the reference currents for shunt active power filters under different load conditions. In PHC method was applied to a three-phase four wire system in order to reduce harmonics present in the source current. When the non- linear load connected across the source, source current getting harmonics, due to the harmonics load heated very short time so to avoid this problem to reduce the harmonics present in the source current. This compensation method will generate un- compensating current to compensate the source current. These methods produce more optimal solution based on the MATLAB simulation.
\end{abstract}

Key words: Shunt Active Power Filter (SAPF), Perfect Harmonic Cancellation (PHC) method, Point of common coupling (PCC).

Cite this Article: A. Muthuraman and M. Saravana Kumar, PHC Control Method for Shunt Active Power Filters in Three-Phase Four-Wire Systems. International Journal of Electrical Engineering and Technology, 11(4), 2020, pp. 384-391.

https://iaeme.com/Home/issue/IJEET?Volume=11\&Issue $=4$

\section{INTRODUCTION}

Power electronic devices and inductive load are more widely used in industrial, commercial, and domestic applications, due to more inductive load cause to drawing non- sinusoidal current and reactive power from the source. This more reactive power consumption causes voltage distortion that affects other loads connected at a point of common coupling (PCC). The Active power filters (APFs) are being developed as a possible alternative to this problem. The block diagram of control method for a shunt active power filter (Fig.1) generates the reference current, that has got to be provided by the active filter to compensate reactive power and harmonic currents required by the load. This method includes a group of currents within the limit of phase domain, which can be traced the generating signals applied to the converter 
by means of the closed-loop switching control technique like PWM control, hysteresis current control or dead-beat control. This is used to calculate the compensating current in terms of the reference source current.

$$
i_{\text {Cref }}=i_{L}-i_{\text {Sref }}
$$

The proposed control is perfect harmonic cancellation (PHC) method, for the calculation of the reference currents during a shunt active power filter connected to a three-phase fourwire system, which supplies an un-compensating current to compensate requirement of reactive current in nonlinear load (Fig. 1). The simulations under both ideal and distorted mains voltage conditions are presented.[1]

The perfect harmonic cancellation (PHC) method is often considered a modification of classical p-q compensation, UPF compensation technique and indirect $\mathrm{p}-\mathrm{q}$ compensation theories. Its objective is to compensate all the harmonic currents and the fundamental component reactive of power demanded by the load. The source current is in phase with the elemental positive-sequence component of the voltage at the PCC [8].

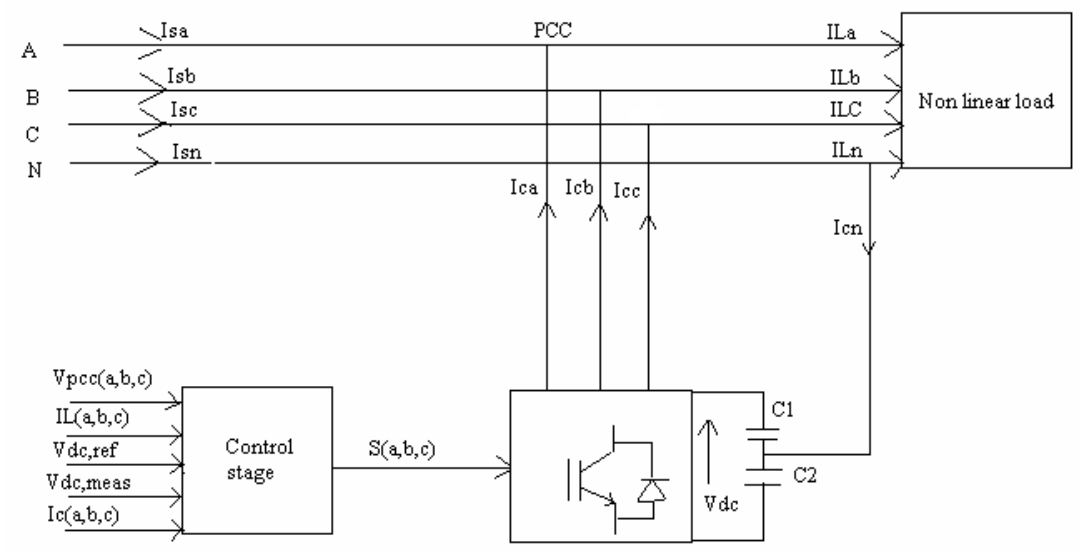

Figure 1 Three phase four wire sources with nonlinear load and shunt active power filter.

The load active power is calculated as follows

$$
P(t)=i_{r} v_{r}+i_{y} v_{y}+i_{b} v_{b}=P_{d c}+P_{a c}
$$

Then only fundamental component of load voltage are taken for calculating the desired current.

$$
\left(\begin{array}{c}
i_{o d} \\
i_{\alpha d} \\
i_{\beta d}
\end{array}\right)=\frac{P_{d c}}{\left(e_{\alpha}\right)^{2}+\left(e_{\beta}\right)^{2}}\left(\begin{array}{c}
0 \\
e_{\alpha} \\
e_{\beta}
\end{array}\right)
$$

Where $e_{\alpha}$ and $e_{\beta}$ are the fundamental components of load voltage and calculated from original voltages by means of ordinary filter circuits like Low-pass filter and band-pass filters. [8]

The reference source current is be given by

$$
i_{\text {Sref }}=K \cdot u_{1}^{+}
$$

Where $\mathrm{u}_{1}{ }^{+}$is the fundamental component positive-sequence voltage at PCC.

The power delivered by the source will then be

$$
P_{s}=u \cdot i_{\text {sref }}=u \cdot K \cdot u_{1}^{+}
$$

The constant $\mathrm{K}$ will be determined with the condition that the above source power equals the dc component of the instantaneous active power demanded by the load. 


$$
k=\frac{\bar{p}_{L \alpha \beta}+\bar{p}_{L 0}}{\left(u_{0}^{2}+u_{\alpha}^{2}+u_{\beta}^{2}\right)_{d c}}
$$

Finally, the reference source current calculation will be given by $\alpha-\beta-o$ transformation,

$$
\left[\begin{array}{l}
i_{s o_{\text {ref }}} \\
i s \alpha_{\text {ref }} \\
i s \beta_{\text {ref }}
\end{array}\right]=K\left[\begin{array}{l}
u_{0} \\
u_{\alpha} \\
u_{\beta}
\end{array}\right]=\frac{\bar{p}_{L \alpha \beta}+\bar{p}_{L 0}}{\left(u_{0}^{2}+u_{\alpha}^{2}+u_{\beta}^{2}\right)_{d c}}\left[\begin{array}{l}
u_{0} \\
u_{\alpha} \\
u_{\beta}
\end{array}\right]
$$

\section{EXPRESSIONS FOR THE REFERENCE SOURCE CURRENTS}

\subsection{Power Calculation}

Instantaneous power defined as the time rate of energy generation, transmission and utilization. The principle of energy conservation in single phase circuit is the product of voltage and current.

$$
p(t)=v(t) \times i(t)
$$

For polyphase circuit with $\mathrm{N}$ phase, each phase instantaneous power is the sum of active power of each phase

$$
p(t)=\sum_{i=1}^{N} p_{i}(t)=\sum_{i=1}^{N} v_{i}(t) \times i_{i}(t)
$$

The reactive power causes increased in transmission line loss and utilization of power, the power to circulate all the phases calculated on instantaneous basis, the power circulates between source and load can be calculating on the average or rms value. The average value is restricted to the frequency domain, others in time domain, shunt compensator to minimize the reactive power or reactive current required of source current. Utilization of energy requires the active power of compensator to average zero $p_{s}(t), p_{L}(t), p_{c}(t)$ is instantaneous power, load and compensator respectively. The average value of power over the time interval $T_{C .}[10]$

$$
P_{x}(t)=\frac{1}{T C} \int_{t-T C}^{t} p_{x}(\tau) d \tau
$$

Where $\mathrm{X}=$ source power $(\mathrm{S})$, Load power (L) and compensator power (c)

Then $P_{S}(t)+P_{C}(t)=P_{L}(t)$

The instantaneous active current $i_{p}(t)$ and non-active current $i_{q}(t)$ are

$$
\begin{aligned}
& i_{p}(t)=\frac{P_{L}(t)}{V_{P}^{2}(t)} \times v_{p}(t) \\
& i_{q}(t)=i_{L}(t)-i_{P}(t)
\end{aligned}
$$

The average load active power and reactive power calculated over the interval of $[t-T c, t]$ is,

$$
\begin{gathered}
P_{L}(t)=\frac{1}{T C} \int_{t-T C}^{t} p_{L}(\tau) d \tau \\
Q(t)=\frac{1}{T C} \int_{t-T C}^{t} v(\tau) i_{q}(t) d \tau
\end{gathered}
$$

Calculating reference source current in PHC method, the equation can be derived from the instantaneous value of active current $i_{p}(t)[10]$ 


\subsection{PHC Strategy}

The equation for reference source current derived based on the instantaneous active and nonactive current with $\alpha-\beta-o$ transformation.

$$
\left[\begin{array}{l}
\text { iso }_{r e f} \\
{\text { is } \alpha_{\text {ref }}}_{i s \beta_{\text {ref }}}
\end{array}\right]=\frac{\bar{p}_{L \alpha \beta}+\bar{p}_{L 0}}{\left(u_{\alpha 1}^{+2}+u_{\beta 1}^{+2}\right)_{d c}}\left[\begin{array}{c}
0 \\
u_{\alpha 1}^{+} \\
u_{\beta 1}^{+}
\end{array}\right]
$$

Where is the reference voltage, its RMS value of the average load active power, both are calculated in the averaging interval power. For a three-phase system, can be expressed in the vector form used in this below equation.

$$
i_{\text {Sref }}=i p=\frac{\bar{p}_{L}}{\left(u_{P 0}^{2}+u_{P \alpha}^{2}+u_{P \beta}^{2}\right)_{d c}}\left[\begin{array}{l}
u_{P 0} \\
u_{P \alpha} \\
u_{P \beta}
\end{array}\right]
$$

The generalized reactive power theory is not specify the characteristics of the voltage $\mathbf{v}(\mathrm{t})$ and current $\mathbf{i}(\mathrm{t})$, they can be theoretically any waveforms. In a power system, the voltage is usually sinusoidal with/without harmonic distortion, and the distortion of the voltage is usually lower than that of the currents. Therefore the voltage is assumed to be periodic for all cases.[11]

If $T_{C}$ is the fundamental period, $T_{1}$ and $v_{p}=v_{p c c}$, by selecting $v_{p}=v_{p c c}^{+}$the PHC reference source current is calculated. The simulations were conducted with both sinusoidal and distorted mains voltage and under different load current conditions. In both cases the phase angle between the fundamental components of source voltage and load current was $30^{\circ}$ degree inductive. For a three phase foure wire system, the equivalent voltage, current, and apperent power are given by

$$
\begin{gathered}
U e=\sqrt{u R^{2}+u Y^{2}+u B^{2} \frac{1}{3}} \\
I e=\sqrt{I R^{2}+I Y^{2}+I B^{2} \frac{1}{3}} \\
S_{e}=3 \text { UeIe }
\end{gathered}
$$

The total active power is obtained by adding the active power in each phase

$$
P=\sum_{k} \sum_{h} U_{K h} I_{K h} \operatorname{Cos} \varphi_{K h}
$$

Where $\mathrm{k}$ means the phase $(\mathrm{R}, \mathrm{Y}, \mathrm{B})$, this the order of the harmonic voltage and $\varphi_{K h}$ is the angle between the $h^{\text {th }}$ harmonic voltage and the $h^{\text {th }}$ harmonic current for phase $\mathrm{k}$. the total power factor of the system is given by

$$
P F=\frac{P}{S_{e}}
$$

The PHC method correctly compensates the fundamental reactive power with unity displacement power factor.

\section{ANALYSIS OF PHC CONTROLLER}

3-phase, 4-wire SAF is composed by voltage source inverter with PWM current control, the input of the controller are phase voltage and line currents the instantaneous current calculated by VSI have higher order harmonics due to its high frequency switching, therefore a shunt 


\section{A. Muthuraman and M. Saravana Kumar}

active filter used to cut off the harmonics. The hysteresis current controller to inject reference current through $\alpha-\beta-o$ transformation.[5]

This method is unable to compensate the dc zero-sequence active power demanded by the load, so that an external source would be needed in such situations. This problem could be obviated if were replaced by

$$
\left[\begin{array}{l}
i_{s o_{r e f}} \\
i s \alpha_{r e f} \\
i s \beta_{r e f}
\end{array}\right]=\left(\frac{P L \alpha \beta+p L o}{\sqrt{u_{\alpha}^{2}+} u_{\beta}^{2}}\right)_{d c} \frac{1}{\sqrt{u_{\alpha}^{2}+} u_{\beta}^{2}}\left[\begin{array}{c}
0 \\
u_{\alpha} \\
u_{\beta}
\end{array}\right]
$$

PHC: This method ensures the sinusoidal and balanced currents in phase with positive fundamental harmonic voltages, although harmonics and/or imbalance appear in the PCC voltage. However, the source delivers reactive power and ac components of active power so that $\mathrm{PF}$ is less than unity.[1]

\section{SIMULATION MODEL}

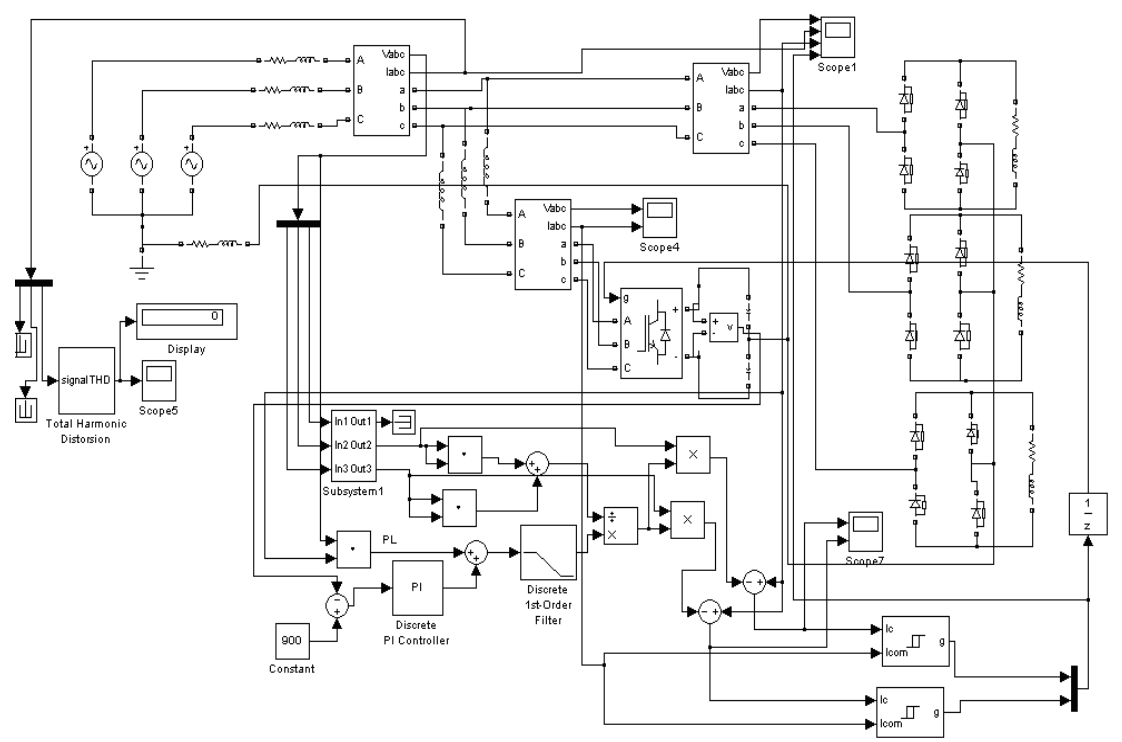

Figure 2 Simulation diagram for PHC Method.

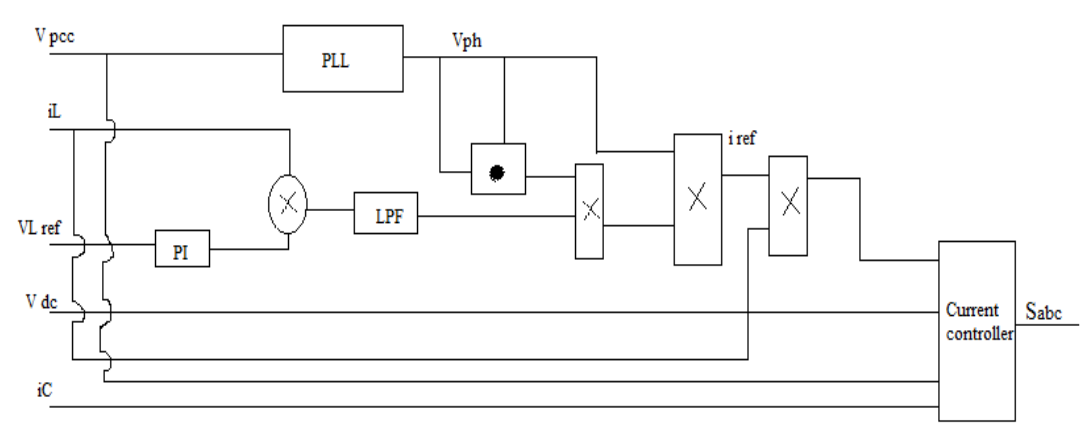

Figure 3 Control stage scheme formed by the PHC control strategy block and the current controller. 
PHC Control Method for Shunt Active Power Filters in Three-Phase Four-Wire Systems

\subsection{Simulation Results}

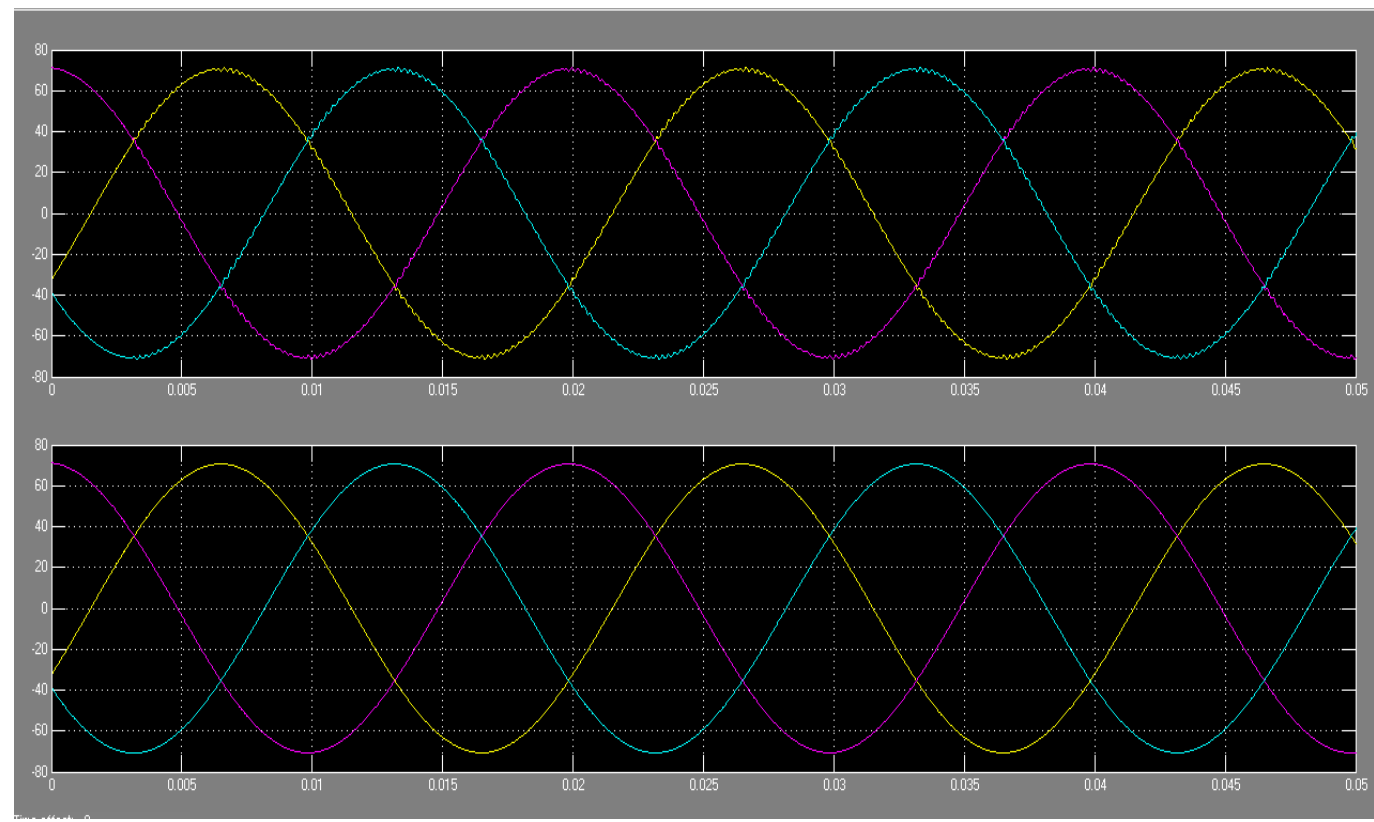

Figure 4 Source voltage And Source Current before compensation

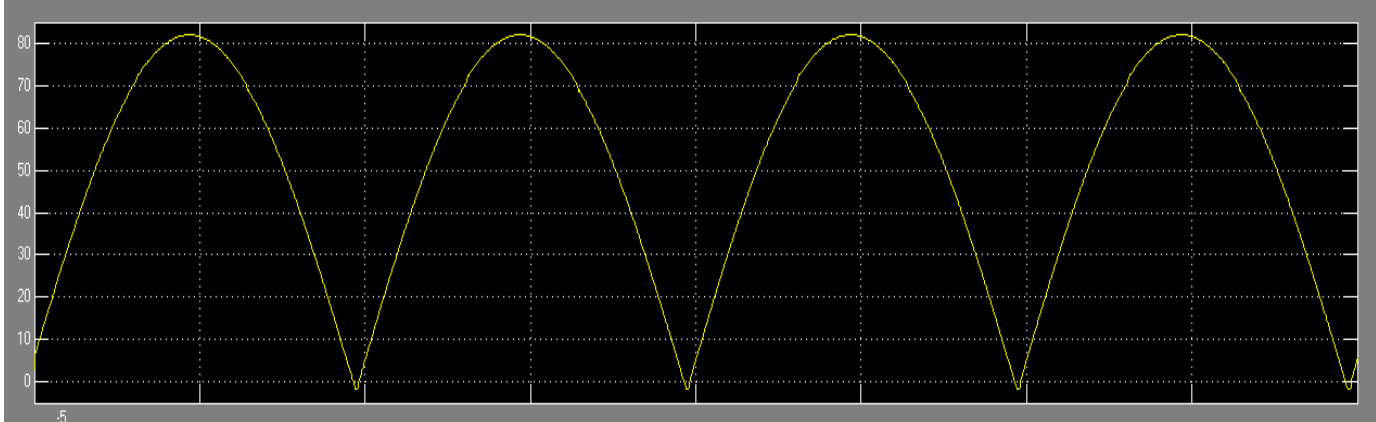

Figure 5 Voltage across the capacitor

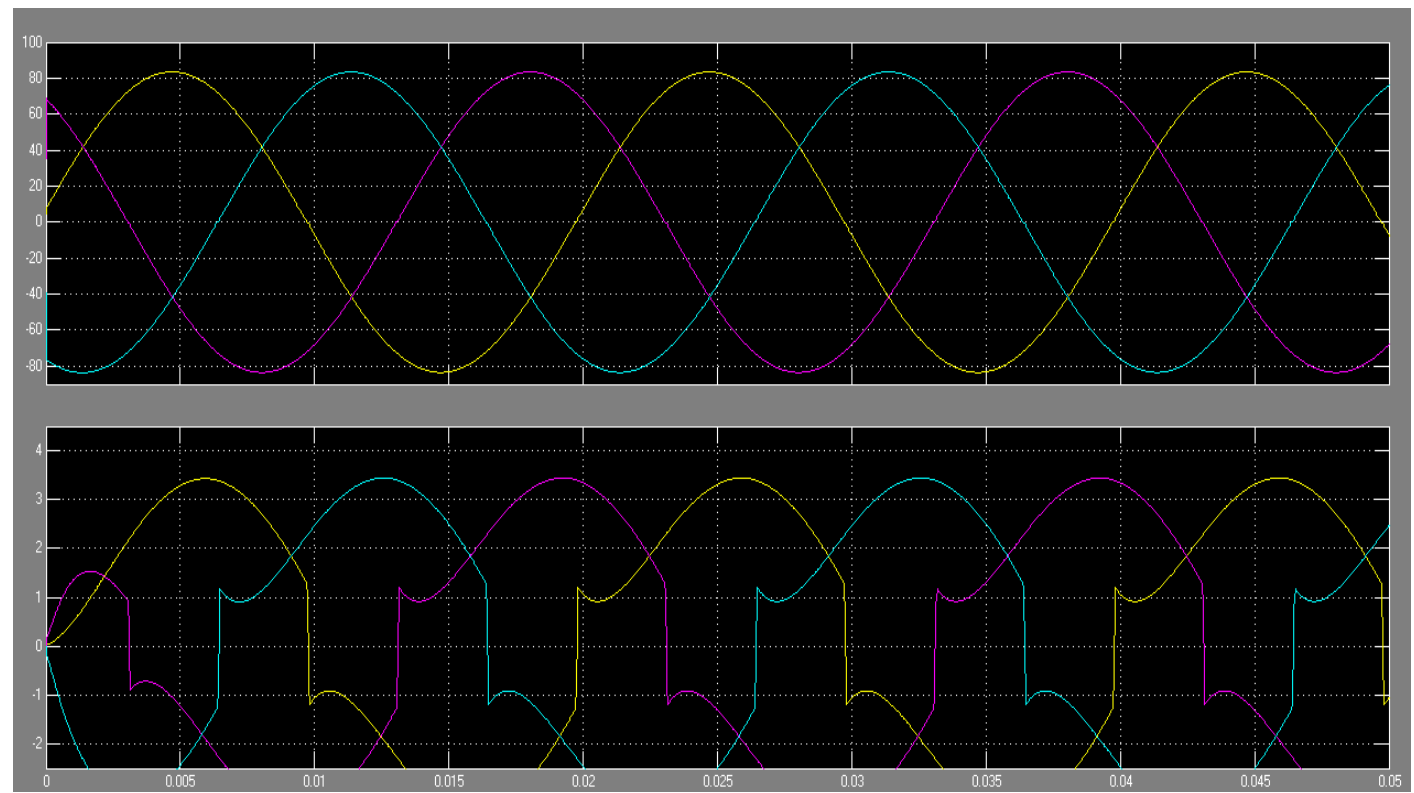

Figure 6 Source voltage before and after non linear load 


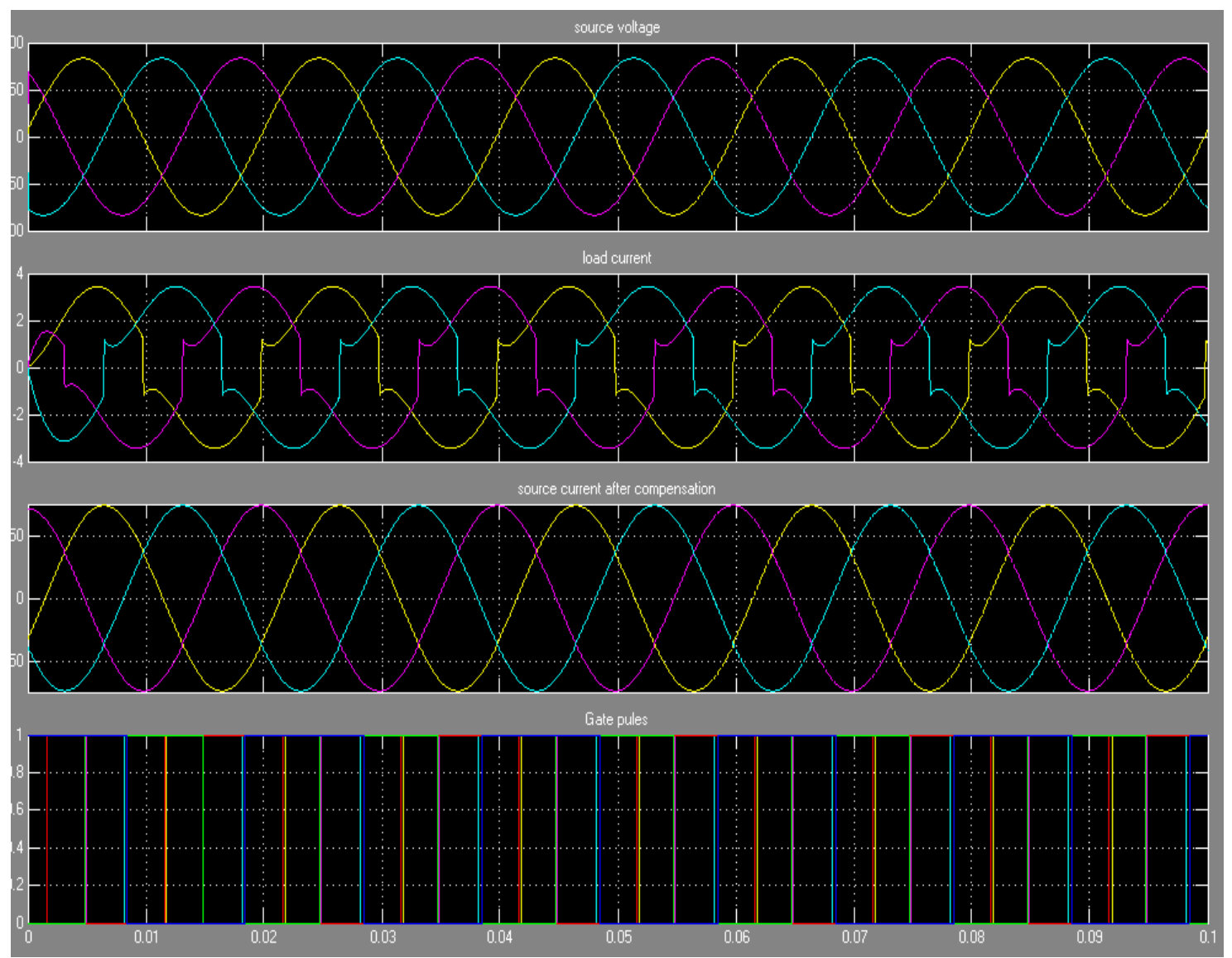

Figure 7 Simulation results for PHC load current, source current after compensation.

\section{CONCLUSION}

This paper has provided control of shunt APFs in three-phase four-wire systems with harmonic distortion or imbalance. These methods are the most sensitive to distortion and imbalance in the voltages at the PCC. Although it is to attain unity PF and to minimize the source current RMS values, three-phase four-wire systems with zero-sequence components in the voltage. The simulations show that source voltage and source current before compensation and after compensation also gate pulse provided to the control circuits with reactive power compensation, this was confirmed by MATLAB simulink Simulation.

\section{REFERENCES}

[1] H. Akagi, Y. Kanazawa, and A. Nabae, (1984) "Instantaneous reactive power compensators comprising switching devices without energy storage components," IEEE Trans. Ind. Appl., vol. IA-20, no. 3, pp. 625-630, May/Jun.

[2] F.-Z. Peng, G. W. Ott, and D. J. Adams, (1998) "Harmonic and reactive power compensation based on the generalized instantaneous reactive power theory for threephase four-wire systems," IEEE Trans. Power Electron., vol. 13, no. 6, pp. 1174-1181.

[3] J. Afonso, C. Couto, and J. Martins, (2000) "Active filters with control based on the p-q theory," IEEE Ind. Electron. Soc. Newslett., pp. 5-11.

[4] M. Aredes and E. H.Watanabe, (1995) "New control algorithms for series and shunt threephase four-wire active power filters," IEEE Trans. Power Delivery, vol. 11, no. 3, pp. $1649-1656$. 
[5] A. Nabae and T. Tanaka, (1996) "A new definition of instantaneous active reactive current and a power based on instantaneous space vectors on polar coordinates in three phase circuits," IEEE Trans. Power Delivery, vol. 11, no. 3, pp. 1238-1243

[6] V. Soares, P. Verdelho, and G. D. Marques, (2000) "An instantaneous active and reactive current component method for active filters," IEEE Trans. Power Electron., vol. 15, no. 4, pp. 660-669.

[7] M.-R. Rafiei, H. A. Toliyat, R. Ghazi, and T. Gopalarathanam, (2001) "An optimal and flexible control strategy for active filtering and power factor correction under nonsinusoidal line voltages," IEEE Trans. Power Delivery, vol. 16, no. 2, pp. 297-305.

[8] A. Cavallani and G. C. Montarani, (1994) "Compensation strategies for shunt active-filter control," IEEE Trans. Power Electron., vol. 9, no. 6, pp. 587-593.

[9] Y. Xu, L. M. Tolbert, F. Z. Peng, J. N. Chiasson, and J. Chen, (2003) "Compensationbased nonactive power definition," IEEE Power Electron. Lett., vol. 1, no. 2, pp. 455-450.

[10] M. Depenbrock, V. Staudt, and H. Wrede, (2003) "A theoretical investigation of original and modified instantaneous power theory applied to four wire systems," IEEE Trans. Ind. Appl., vol. 39, no. 4, pp. 1160-1168, Jul./Aug.

[11] IEEE (1996) Working Group on Nonsinusoidal Situations: Effects on Meter Performance and Definitions of Power, "Practical definitions for powers in systems with nonsinusoidal waveforms and unbalanced loads: a discussion," IEEE Trans. Power Delivery, vol. 11, no. 1, pp. 79-101.

[12] A. E. Emanuel, (2004) "Summary of IEEE Standard 1459: definitions for the measurement of electric power quantities under sinusoidal, nonsinusoidal, balanced, or unbalanced conditions," IEEE Trans. Ind. Appl., vol. 40, no. 3, pp. 869-876, May/Jun.

[13] R.J.Motiyani, Mr.A.P.Desai, (2013) Three Phase Shunt Active Filter with Constant Instantaneous Power Control Strategy, International Journal of Electrical Engineering and Technology, 4(4), pp. 245-254.

[14] Smita Singhai, Bharti Dewani, (2013) PLL Based Shunt Active Harmonic Filter to Compensate Multiple Non-Linear Loads, International Journal of Electronics and Communication Engineering \& Technology, 4(4), pp. 198-205 